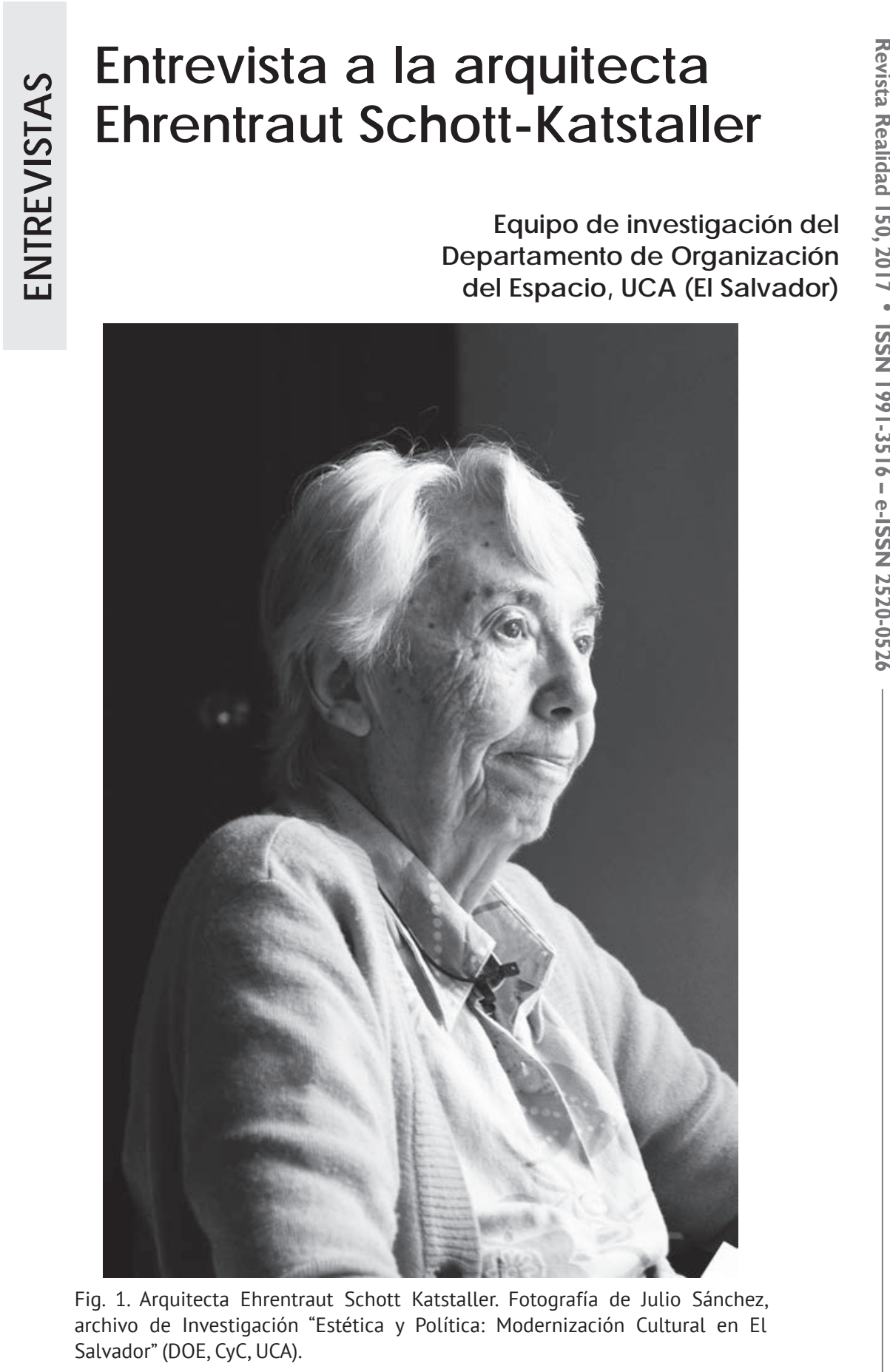


Ehrentraut Schott-Katstaller nació en Austra en el año de 1924. Se recibió de arquitecta en la Universidad Técnica de Viena en 1945, de ingeniera civil en la Universidad Técnica de Graz en 1948, y obtuvo un título en Artes de la Academia de Bellas Artes de Viena en 1950. Llegó a El Salvador en 1952, junto a su esposo Karl Katstaller, igualmente arquitecto e ingeniero. Ambos se incorporaron al equipo de diseño de la Dirección de Urbanismo y Arquitectura (DUA), en ese mismo año. A partir de 1958, abrieron su propio estudio de arquitectura, combinando su práctica profesional con la docencia. Se incorporó como arquitecta a la Universidad de El Salvador en 1965, convirtiéndose así en la primera mujer en obtener ese título en el país. Entre las obras más destacadas de su vasta producción se puede mencionar el Estadio Óscar Quiteño en Santa Ana, la Escuela Nacional de Agricultura (ENA), así como la Capitanía y Aduanas del Puerto de Acajutla. La presente entrevista tuvo lugar el lunes 10 de diciembre de 2012, en su residencia de Antiguo Cuscatlán. Entrevistaron Sofía Rivera y Sandra Gutiérrez.

Sofía Rivera (SR): Para iniciar la entrevista, como le comentó Sandra, nos interesa mucho conocer sobre su formación, algunos datos personales que usted nos quiera compartir y en específico dónde realizó sus estudios iniciales y en qué fechas. En sus estudios y formación quisiéramos saber qué arquitectos consideraría como los que más influyeron en usted. $\mathrm{Y}$, posteriormente, la gran pregunta: ¿qué los trajo a usted y a su esposo a El Salvador?

\section{Ehrentraut Schott-Katstaller} (ESK): Bueno, para principiar yo nací en Austria en Viena, ahí estuve en la escuela primaria y secundaria. Después de la secundaria estudié en la Universidad de Viena, en la Universidad Técnica. Esto fue durante la Segunda Guerra Mundial. Los estudios en este tiempo, más bien las lecciones de los profesores, a veces se hacían en los sótanos, por las bombas que caían. Después fue el final de la guerra y yo ya no seguí en Viena porque la vida era muy difícil allá, porque ya estaba la ocupación por los rusos. Nuestra familia se fue a un estado de Austria. Allá trabajé por un año con un arquitecto. Hicimos varios proyectos no muy grandes en ese tiempo, porque era el primer tiempo de posguerra, nadie tenía financiamiento.

Hicimos unas reconstrucciones de edificios que valían la pena reconstruir, porque eran del tipo barroco o del renacimiento. En Innsbruck, en la capital de Tirol, también hicimos el diseño de un cine en un pueblo. Después de estar ahí, yo me fui a Alemania y trabajé con quien después iba a ser mi esposo, Karl Katstaller. Nos conocimos en la Academia de Bellas Artes en Viena donde yo hice un posgrado $y$ 
él se fue como una recomendación del profesor a un pueblo cerca de Frankfurt. Yo también me fui para allá a trabajar junto a él. Trabajamos allá como dos años, y siempre comprábamos una revista de ingenieros y arquitectos, donde salió un artículo muy chiquitito donde se decía que dos ministros de El Salvador habían venido a Alemania, estaban en Hamburgo y estaban buscando a quien dar el proyecto para la reconstrucción de dos pueblos que habían sido destruidos por un terremoto: Chinameca y Jucuapa. Nosotros pensábamos que este trabajo se haría allá en Alemania y después se enviaría el proyecto a El Salvador, pero no fue así. Cuando fuimos al consulado general de El Salvador en Hamburgo nos dijeron que ya tenían preparado el contrato "ahí está el contrato, fírmenlo", y nosotros dijimos "bueno no vamos a firmar si no sabemos qué firmamos", porque el contrato era en español y nosotros no sabíamos el idioma. Entonces nos recomendaron un traductor, nos tradujeron el contrato y él también tenía conocidos alemanes que vivían en El Salvador. $Y$ el traductor nos dijo: "mire ahí está ese señor por casualidad, le vamos a preguntar", y éste dijo "si les recomiendo ir allá, porque lo que ofrece el gobierno lo cumple".

Nos mandaron el ticket, el boleto del avión, y cerramos todo lo que teníamos allá. Teníamos todavía un proyecto de trabajo que dejamos a un colega y nos fuimos de viaje. Primero, nos fuimos con unos amigos para despedirnos del Rin, y como era un día domingo había mucho tránsito... bueno no tránsito como hoy, pero para el tiempo de entonces ya era un tránsito un poco más fuerte,y el amigo nuestro que manejaba el vehículo se puso nervioso y no manejaba muy rápido y ya nosotros sabíamos que el avión se iba ir sin nosotros, pero nos esperaron. Allí estaban unos amigos para despedirnos, y escucharon llamar nuestros nombres, que nos presentáramos en el mostrador, y ellos les dijeron que nos esperaran. $Y$ dijeron que esperarían un momento todavía, que sólo fueron a despedirse. Al llegar al aeropuerto ni pudimos despedirnos, agarraron nuestras valijas y las metieron al avión y a nosotros también, a empujones en las gradas, todavía había que subir gradas, no había esos conductos que hay ahora, era la línea holandesa.

Entonces, primero fuimos a Ámsterdam, ya era de noche y como a finales de abril, el 30 o 29 abril del año 1952. Mi esposo, a quien le gustaba mucho la ensalada de pepino, dijo: "bueno aquí en Holanda ya en este tiempo debe de haber ensalada de pepino". Y el mozo se desapareció, y en un momento llegó con la ensalada de pepino a servirla. Entonces, ahí estuvimos esperando para seguir; nos llevaron primero de Ámsterdam, a Islandia arriba casi en el polo norte. Después fuimos al 
sur, a Curazao, Maracaibo, Panamá y después, con el lechero, a El Salvador. Era un avión chiquito. Cuando pasamos por el Irazú, el piloto mandó a decir que si ya habíamos sacado la foto del volcán o si él debía de dar otra vuelta para que sacáramos otra foto, era todo muy familiar.

Llegamos al aeropuerto de Ilopango,y ahí estaban esperándonos Lito Cordero y Martin Schultz. ${ }^{1}$ Martin Schultz hablaba alemán y Lito Cordero hablaba inglés y español, entonces llegaron en dos vehículos y mi esposo se fue en el carro con los que hablaban alemán y yo, con Lito Cordero que hablaba inglés. Pasamos entonces por Soyapango, veíamos las champas y yo pensaba que eso era San Salvador. Me dije: "bueno no voy a preguntar porque tal vez se sientan incómodos". Después llegamos a una zona un poco más bonita que era el pasaje Guirola y Lito dijo: "bueno ahora no sé a dónde la tengo que dejar”. Pero, al fin, sí encontró el lugar. Entonces ya habían preparado los cuartos. Llegó Antonieta, que era la propietaria de la pensión; ella habló mucho y muy rápido y nosotros no entendíamos nada, sólo asentíamos. Al día siguiente en la mañana, ahí estaban también Martin Schultz y un italiano que trabajaba en la vivienda, creo. Este italiano cuando se fue en la mañana a tomar su ducha con entusiasmo cantó "O sole mio!", y yo no sé qué más.
Después nos llevaron a Obras Públicas. ${ }^{2}$ Esto era en la $10^{a}$ avenida sur. Las instalaciones estaban hechas de lámina, se puede decir. Las mesas estaban listas, pero en la noche, como ya era tiempo de lluvias, cayeron las lluvias sobre la mesa y entonces tuvimos que proteger nuestros dibujos con plástico, para que no se nos arruinaran. Yo trabajé allí hasta el 58. Para ese entonces, me había incorporado en la Universidad para poder trabajar en el sector privado. Tuve que hacer un examen y me dieron el título de la Universidad de El Salvador. Ya tenía mi tercer o cuarto título, porque yo saqué uno en la Universidad Técnica de Viena, otro en la Academia de Bellas Artes en Viena y, después, el título en El Salvador. Pero no los tengo enmarcados sino guardados. Bueno, qué más quieren saber.

Sandra Gutiérrez (SG): Después de esa etapa, cuando se integró a El Salvador, ¿estuvo trabajando en la dirección de urbanismo y arquitectura?

ESK: Sí, en el Departamento de Arquitectura. Había Departamento de Arquitectura y Departamento de Urbanismo, que diseñaban las calles y las carreteras. Entonces nosotros estuvimos en el Departamento de Arquitectura diseñando. Yo hice varios mercados y alcaldías. 
SR: ¿Su esposo trabajó más en la red de escuelas?

ESK: Yo también, los dos. Yo diseñé las escuelas de Chalatenango, Guazapa y Aguilares, y también la de San Francisco Gotera, eso estaba lejos. Nosotros conocimos el país por todos los rincones, porque siempre donde había que hacer un proyecto, nosotros íbamos a conocer el lugar. Una vez fuimos a Apopa a diseñar la alcaldía de allá y había árboles muy bonitos en el lugar, entonces yo mandé a los topógrafos a que me pusieran todos los árboles en el plano, para respetarlos, lo que se podía. Mi proyecto estaba hecho de tal manera que los árboles se conservaran, no todos, pero la mayor parte. Cuando llegué allá otra vez, ya no había ningún árbol. El alcalde, muy feliz, me enseñó el lugar: "mira qué lindo quedó". Y yo dije: “¿dónde están los árboles?" y él me respondió: "limpiamos el terreno". Yo le contesté: "mire, nosotros tratamos de conservar los árboles y ustedes los botaron". Me imagino que él quería la madera, así me dijeron después. Esas eran las primeras experiencias, fuimos a Nahuizalco, bueno conocí casi todo el país, se puede decir, con estos viajes para conocer los lugares donde se hacían los proyectos.

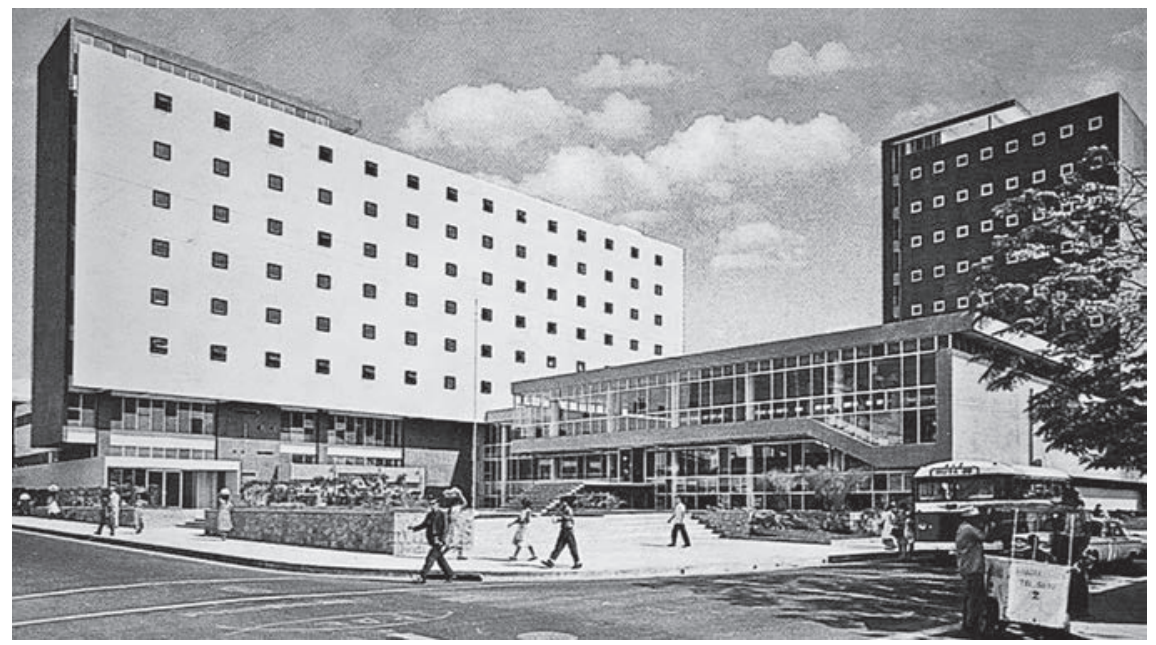

Fig. 2. Biblioteca Nacional y Ministerio de Educación. Diseño de Ehrentraut Schott Katstaller (1959).

SR: Nosotras ahorita estamos mercado de Coatepeque, ése que haciendo viajes buscando los todavía existe... proyectos, hace poco visitamos el 
ESK: ¿Todavía existe? Bueno, Coatepeque tienen más movimiento, porque a veces van al lado, quizá bajan al mercado a buscar algo... Sí, ya no recuerdo todos. Hay uno en este pueblo, que está en el trayecto entre San Vicente y Zacatecoluca... ¡Ah! Tecoluca. También este mercado hice, el de Apopa, el de Quezaltepeque. En Guazapa y Aguilares hice las escuelas, en San Francisco Gotera la escuela... En Acajutla, allí mi esposo hizo el edificio de administración portuaria. Bueno, casi en todos los pueblos dejamos algún rastro... Algunos edificios los conservaron, algunos se deterioraron, porque nunca pensaron en conservarlos. Esto también cuesta dinero y para esto no había ningún presupuesto, sólo para edificios nuevos pero para los que existían, para conservarlos, lo dejaron a los alcaldes, y los alcaldes a veces se preocupaban 0 a veces los profesores o los directores de las escuelas. En Guazapa era muy divertido,éste sí estaba bastante bien conservado, pero en la biblioteca estaban las gallinas del director y él, con su familia, vivía en la dirección... (Risas). Varias veces había sorpresas. También recuerdo un mercado creo... no, era una escuela. La directora se había instalado en los servicios sanitarios, ahí vivía ella...

SR: Arquitecta, en esa época cuando trabajaban con el lugar, era un equipo que trabajaba de varios arquitectos e ingenieros...
ESK: Sí, pero cada quien hacía sus proyectos...

SG: ¿Y había muchas mujeres?

ESK: No, yo era la única al principio, después vino Maribel Arrieta, la reina de belleza de El Salvador. Ella vino a trabajar, pero el trabajo de ella no era mucho, más bien estaba sentada en una mesa de trabajo y alrededor de ella estaban sus admiradores. Era divertido...

SG: Entonces, ¿usted se mantuvo trabajando ahí y al mismo tiempo trabajaba en la Universidad Nacional?

ESK: Sí, estuvimos de profesores, temprano en la mañana y tarde en la noche, y en el día trabajábamos en Obras Públicas.

SG: ¿También era un mundo de hombres la Facultad o ya habían más mujeres?

ESK: Yo era la única mujer también en ese tiempo.

SG: Entonces, iusted ha sido una pionera en este país para las mujeres?

ESK: Sí, yo era la única mujer primero en Obras Públicas y luego en la Universidad. Bueno, eso fue hace tiempos, en el 52 vinimos al país y en el 56 o 58 empezamos 
a trabajar en la Universidad, allá 60 y cuánto, algunos años estuve en estuve hasta, no recuerdo, el $60 \ldots$ o la Universidad.

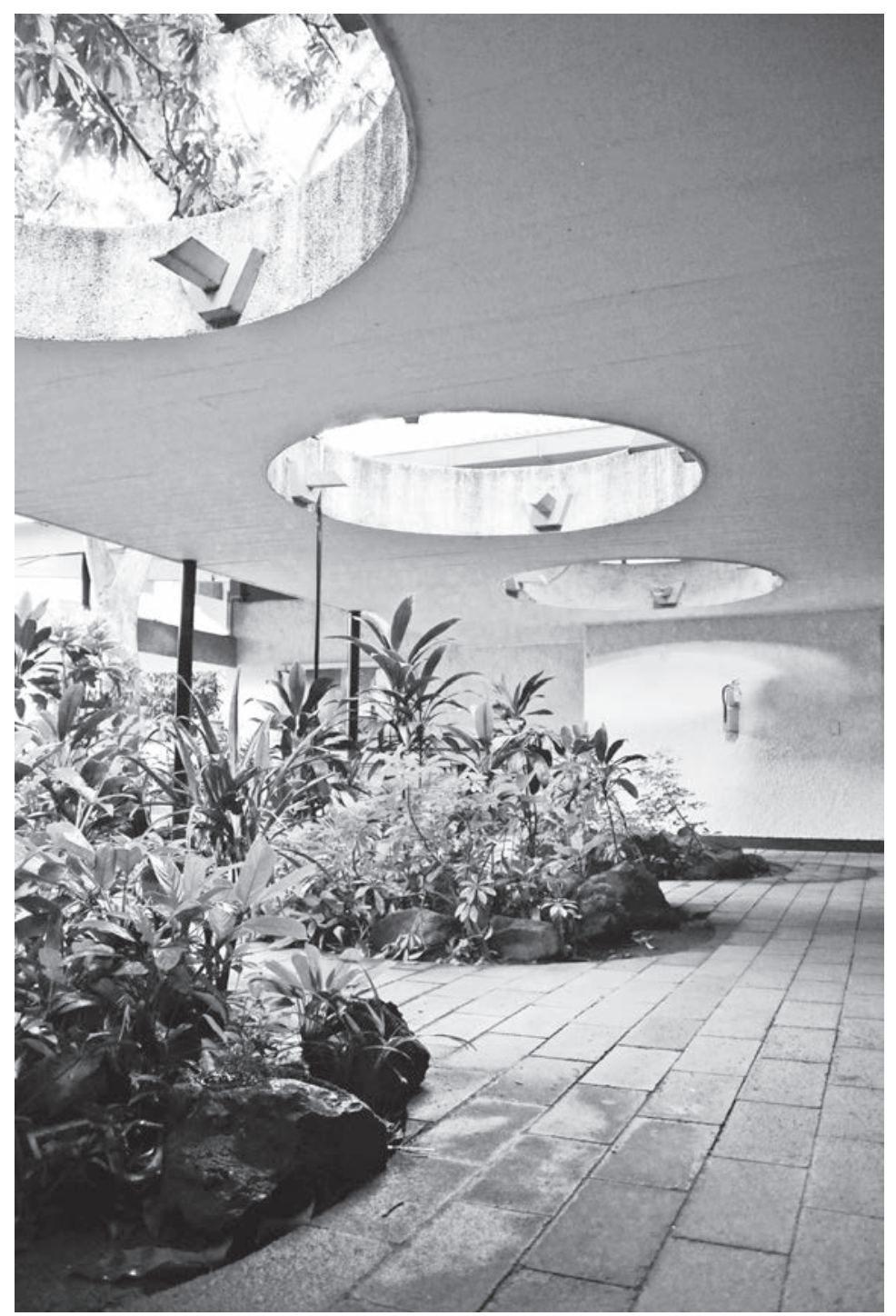

Fig. 3. Pasillo interior de la Escuela Alemana, diseño de Ehrentraut Schott Katstaller (1970). Fotografía de Julio Sánchez, archivo DOE. 
SR: ¿Y cómo era el ambiente de enseñanza?

ESK: El ambiente era muy bonito en esos tiempos. Después que dejé de trabajar en la Universidad, cuando se politizaron entonces yo dije:"como extranjera no puedo meterme en la política". Entonces, me empezaron a pedir firmas y cosas así, y yo dije que no, lo siento mucho, ya no puedo trabajar en estas circunstancias, y lo entendieron.

SR: ¿Y quiénes trabajaban en ese momento en la Universidad?

ESK: Lito Cordero creo, Óscar Reyes también, Edmundo Kury y de ingeniero era el ingeniero... bueno, Martin Schultz también estuvo allá y Posada. Posada también estaba con nosotros cuando trabajábamos en lo privado. Él hacía siempre los cálculos estructurales de nuestro proyecto.

SG: Mientras estuvieron trabajando en la Universidad, ¿también tenían otros proyectos con su esposo?

ESK: ¡Ah! Cuando, después de haberme titulado en la Universidad, empecé a trabajar en lo particular, porque esto se tenía que tener, tuvimos que estar inscritos y matriculados, más bien graduados de la Universidad. Yo hice el examen con Edmundo Kury, creo, y no recuerdo quién más, Óscar Reyes parece.
Con ambos habíamos trabajado. El proyecto para el examen era un hospital en La Libertad. Me dieron el proyecto en la noche y al día siguiente tenía que presentarlo, entonces tenía que trabajar allá en la Universidad solita toda la noche. Yo dije: "no me voy a quedar de noche". Me fui a mi casa a dormir y, después en la mañana, hice unas líneas y lo llevé.

SR: Regresando un poco a sus primeros proyectos, habló de Jucuapa y Chinameca, los mercados y escuelas. Nos damos cuenta que en mucho diseño del trópico, ustedes tomaban mucho en cuenta la temperatura y aspectos que son propios de aquí, de El Salvador...

ESK: Bueno, nosotros hicimos los proyectos para El Salvador. No los hicimos para Austria. Entonces, lo que hicimos nosotros cuando venimos al país, cuando nos instalamos aquí, teníamos solamente nueve meses, el contrato con Obras Públicas que firmamos allá en Alemania era por nueve meses; pero, si ambos, tanto el Gobierno como nosotros estamos de acuerdo, podíamos seguir trabajando, y eso hicimos. Entonces yo me quedé hasta el 58 y mi esposo, creo que hasta el 61 (en Obras Públicas), y después trabajábamos en lo privado entre los dos. En Obras Públicas hicimos muchos proyectos de escuelas y yo hice también muchos mercados. Me interesaba mucho lo que hacíamos. Por ejemplo, cuando había que 
hacer el diseño para un mercado en un pueblo, nos íbamos al pueblo a ver primero el lugar, donde estaría el mercado, platicábamos con la gente. Vimos que las damas de edad estaban sentadas con su canasto en el piso y esto, francamente, no nos gustaba mucho, porque en el piso tropezaba la gente que caminaba. Preparamos unas mesitas hechas de concreto, donde podrían poner las canastas. Lo que hicimos, la mayor parte de concreto también, fueron las cocinas. Las mesas eran de concreto, porque nos dimos cuenta que cuando no era de un material resistente se arruinaban bien rápido, entonces era un desastre. Esta fue la razón por la que hicimos mesas de concreto, bancas de concreto. Los mercados los hicimos con buena ventilación. Esto sí es primordial, sobre todo en lugares donde hacía mucho calor. También, por ejemplo, en edificios como el edificio del puerto de Acajutla, usamos sunblind que evita que el sol entre a las ventanas, y están separados de las ventanas, para que siempre haya circulación de aire.

Esto también lo podrían observar en la escuela de Aguilares, allí también pusimos estos sunblind, esta lámina acanalada, y también en Guazapa. Siempre hemos previsto que haya una buena ventilación y no hicimos un salón de actos cerrado, sino que era más bien para ahorrar área de construcción, porque ustedes saben que cada metro cuadrado vale dinero. Era un pasadizo de comunicación entre las aulas primarias y las de secundaria, allí en medio estaba el salón de actos, que era un salón abierto, con luces y con sombras. No era cerrado entre sí, y siempre servía de circulación y también servía para los alumnos que en los intermedios se podrían mantener en un lugar fuera de las aulas pero bajo techo, esa era más bien la idea en las escuelas y en los mercados, allí también hicimos techos y ventilación con protecciones contra el sol.

SR: $Y$ entre las personas que siempre estuvieron trabajando con ustedes, ¿cuáles arquitectos salvadoreños usted podría decir que eran los más importantes?

ESK: Bueno, creo que Lito Cordero. Él se murió relativamente joven lastimosamente, pero yo creo que él era muy buen arquitecto.

SR: ¿Cómo describiría su obra y la de su esposo, ya que muchos de los proyectos los hicieron juntos, cómo describiría la evolución de ese lenguaje que desarrollaron, que incluso ahorita, 60 años después, nosotros que buscamos sus proyectos lo vemos y lo reconocemos?

ESK: Eso sí, siempre se dice que el manuscrito tiene que ser la obra, si uno no copia de otro entonces tiene su propio... no quiero decir estilo, 
sino su propia forma de trabajar y de diseñar. Siempre, naturalmente todo estaba influido por el terreno y el clima, por ejemplo: la escuela de Guazapa era en un terreno inclinado y ahí estaba una parte arriba, una parte abajo y en medio el salón de actos abiertos, que ya les expliqué. Siempre nos adaptamos en los terrenos.

SR: Dentro de los otros proyectos que realizaba, aparte de los mercados y las escuelas, nos interesa mucho conocer sobre la Biblioteca Nacional, la cual lastimosamente ya no la podemos visitar, nos puede platicar sobre cuáles fueron sus ideas iniciales de diseño, ¿qué materiales utilizaron?...

ESK: Sí, ya se cayó. Bueno, en la Biblioteca Nacional, uno pensaba en el público que la iba a usar, porque no era solamente Archivo Nacional y libros escondidos, sino que era para el público, y por eso estaba ese gran salón. Aquí pueden ver...

(Baja hasta su estudio para mostrar imágenes sobre sus proyectos).

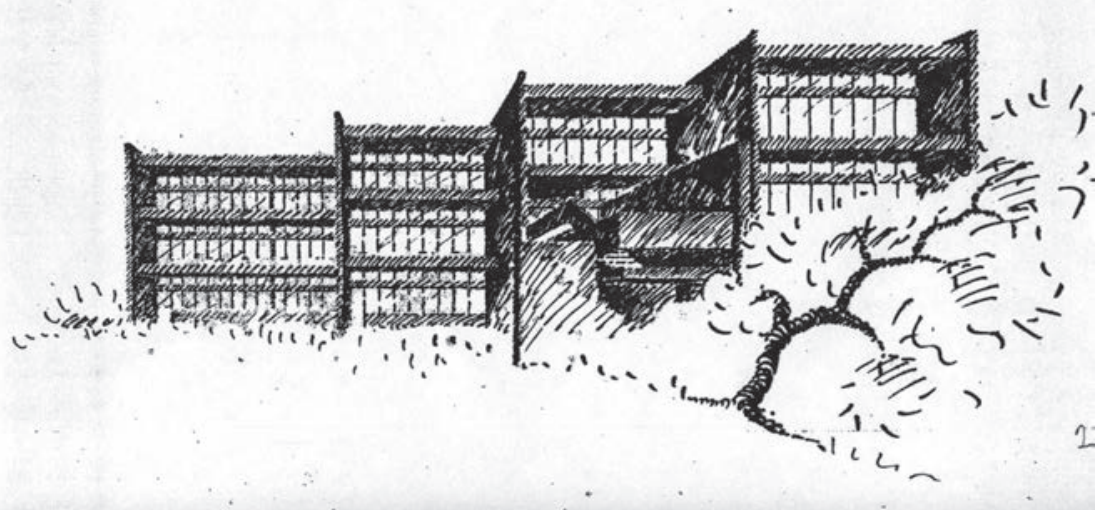

Fig. 4. Boceto de la Escuela Alemana, diseño de Ehrentraut Schott Katstaller (1970). Fuente: archivo personal de Ehrentraut Schott Katstaller. 
ESK: El reto más interesante fue el edificio del comedor y salón de actos en San Andrés...

SG: ¿En la Escuela Nacional de Agricultura?

ESK: No sé si lo conocen, es un edificio de domo, es como una cúpula... Ahora bien, para hacer esa cúpula primero dijeron "no se puede", los ingenieros que estaban en la parte de construcción. Entonces se hizo una maqueta... lo que no recuerdo, algo cambiaron allá que ya no estaba tal

\section{Notas}

1 Lito Cordero (Rafael Cordero) fue un arquitecto salvadoreño, se desempeñó como arquitecto jefe del Departamento de Arquitectura en la Dirección de Urbanismo y Arquitectura (DUA), de 1950 a 1955 aproximadamente, miembro fundador del Grupo Salvadoreño de Arquitectos, profesor de la carrera de Arquitectura de la Universidad Nacional de El Salvador como estaba proyectado, yo no sé si eran las puertas de entrada o algo...

SR: ¿En la construcción?

ESK: Y lo más divertido fue que en el acceso pusieron unos postes con luz, unos postes horribles, esto nos lo enseñaron los vigilantes de allá, estaban muy orgullosos de los postes de luz...

(La entrevista finaliza cuando la arquitecta Ehrentraut Schott-Katstaller muestra el libro de memorias de su empresa Constructa S. A.).

(UES). El ingeniero Martin Schultz ejerció como ingeniero residente dentro del Departamento de Arquitectura de la DUA, al igual que Rafael Cordero ejerció como profesor de la carrera de Arquitectura en la UES.

Ministerio de Fomento y Obras Públicas, actual Ministerio de Obras Públicas (MOP). 